\title{
Handling, reactivity and price of beef cattle
}

\author{
Cinara da Cunha Siqueira Carvalho ID. Evileide Marques de Oliveira ID. Maria Dulcinéia da Costa (iD. \\ Camila Maida de Albuquerque Maranhão iD. Tatiany Carvalho dos Santos ID. Flávio Pinto Monção (iD. \\ Vicente Ribeiro Rocha Júnior (D. José Reinaldo Mendes Ruas iD. Thaís Emanuele Soares iD
}

\author{
CCS Carvalho (Corresponding author) - EM Oliveira - MD \\ Costa - CMA Maranhão - FP Monção • VR Rocha Júnior \\ - JRM Ruas - TE Soares \\ Departamento de Ciências Agrárias, Universidade Estadual de \\ Montes Claros (UNIMONTES), Janaúba, MG, Brazil. \\ email: cinarasiqueira@yahoo.com.br
}

\author{
TC Santos \\ Departamento de Engenharia Agrícola, Universidade Federal \\ de Viçosa (UFV), Viçosa, MG, Brazil.
}

Received: December 09, 2019 - Accepted: February 09, 2020 • Published Online: February 28, 2020

\begin{abstract}
Given the importance of cattle breeding for the Brazilian economy, as well as the growing concern with animal welfare, studies that clearly and objectively approach the way cattle are handled during auctions become necessary. This study aims, hence, at assessing the influence of cattle handling on the reactivity of animals at the time of arrival at the exhibition park. We also aimed to evaluate the impact of reactivity and visual aspects on the price for animals at auctions in the northern region of the state of Minas Gerais. We observed 241 lots of commercial and 43 lots of pedigree cattle in loco, assessing the type of handling and the cattle's behavior when arriving at the exhibition park, accommodation in the corral and loading to the destination. Upon arrival, commercial animals were more reactive than pedigree cattle due to the change of environment - exhibition park as opposed to their original habitat, and also to the number of visitors who induce stress and cause the animals to retreat. Commercial and pedigree females were more reactive than males upon arrival and loading, particularly when close to their offspring. Commercial animals that scored high in aggressiveness had smaller flight zones, for they run toward fences when threatened. Young commercial animals entered the auction ring with no external help due to anxiety and restlessness. The visual aspect influences the price in virtual markets.
\end{abstract}

Keywords: agricultural show, animal temperament, humananimal relation

\section{Introduction}

Beef cattle farming has a prominent place in animal production. Brazil is the country with the biggest cattle herd and is the second-biggest producer of beef in the world. According to the Brazilian Beef Exporters Association
(ABIEC 2019), transactions in the beef market reached 597.22 billion Brazilian Reais in 2018, generating around 353,725 job posts.

The demand for beef products has increased in the last years because of population growth. Brazil, with its tropical climate and vast territory, can meet this demand thanks to the production systems adopted in the country. Brazilian systems use nutritional resources of low relative cost, such as tropical grasses, and farmers raise species well adapted to tropical climate conditions (Hoffmann et al 2014).

As a significant part of the Brazilian beef cattle herd is raised extensively, human-animal interaction is kept to a minimum. This leads to particular animal reactions when in the presence of humans and negative interactions are not favorable to routine handling.

Animal behavior is then of fundamental importance: animals subjected to low-stress handling tend to present lower reactivity and relaxed temperament.

Reactive animals tend to cause problems in everyday handling, but there are several ways of tackling the issue of high reactivity. Among them, we can cite the adjustment of handling practices, which can be done through adequate training of the workforce and the adoption of selection criteria that take the identification of less reactive animals into account (Barbosa et al 2006).

Given the importance of cattle breeding for the Brazilian economy, agricultural shows and exhibitions take place across the country to disseminate novelties and the current status of animal production and genetics through the exhibition of animals in judging contests and auctions.

The results of the type of handling can be observed from the moment when the animals enter the auction ring. The audience present at the exhibition and auction rings, as well as 
those watching the sales through media, have increasingly requested information on the type of handling and behavior of animals.

Hence, assessment of how animals are treated in the referred events and their reaction when removed from their usual habitat is of utmost importance. The handling adopted at arrival at the exhibition park and auctions, when successfully employed, tend to have a positive impact on sales.

Therefore, we aimed at verifying the influence of the type of handling employed on the reactivity of the animals arriving at the exhibition park. Furthermore, we evaluated the impact of reactivity and visual appearance on the price during auctions in the northern region of the state of Minas Gerais.

\section{Material and Methods}

Data collection occurred in two agricultural shows in northern Minas Gerais. The team responsible for handling the animals in the park was the same in both situations.

We evaluated 241 lots of commercial animals and 43 lots of pedigree animals through in loco observations, assessing the type of handling and the behavior of cattle during arrival at the exhibition park, accommodation in the corral and loading to destination.

Commercial cattle were divided into lots with a minimum of 15 animals and put in simple stalls, with access to water but no food. Pedigree cattle were divided into lots of up to 4 animals, kept in the shade and had access to water and food.

A completely randomized design (CRD) was used to analyze commercial animals according to age categories, reactivity scores and the driver's behavior. We also adopted the CRD for pedigree animals and divided them according to sex (male or female). Each sex category was subdivided according to age ( 1 - less than one year old; 2 - animals aged between one to three years; 3 - animals older than three years) and to dirtiness ( 1 - clean animal; 2 - dirty animal).

We classified the driver's behavior or the use of sticks and similar equipment upon arrival according to the following scale: 1 - behavior with no aggressiveness; 2 - use of prod; 3 - use of electrical shock.

\section{Data collection for commercial and pedigree animals in the corral}

Since the trucks did not arrive simultaneously, we carried out the data collection as the animals arrived at the park.

The animals arrived at the park to be sold and were accommodated in the corral or specific stalls and handled according to their category - commercial or pedigree. Thus, we observed the arrival of the animals to assess the type of handling employed, the number of animals per lot, traveling time, access to showers, accommodation place and access to food and water.

Following arrival, the animals were taken to the corral to wait, and 10 minutes later, we observed the following aspects:

Flight zone: we used an electronic digital laser tape measure $\left(\right.$ Insthuterm $^{\odot}$ ). The observer approached the corral and waited for the animals to move away. Once they were calm, the observer pointed the tape measure to the midpoint of the distance to measure the flight zone.

Noise: a digital sound level meter $(1.5 \mathrm{~dB}$ precision, $0.1 \mathrm{~dB}$ resolution, sampling rate of 2 times per second and frequency range of $31.5 \mathrm{~Hz}$ ) was used to verify the level of noise in each lot. It was positioned in front of the lot to assess the intensity of the animals' vocalization.

Reactivity: the approach test adapted from Figueiredo et al (2005) was used to assess the reactivity. A standard subjective score scale was attributed according to the animal's overall reaction to the observer's approach (Table 1).

Table 1 Reactivity scores referring to the animals' reaction following the approach of humans.

\begin{tabular}{ll}
\hline Score & Characterization of the animals' behavior \\
\hline $1-$ Very reactive lot & The animals aggressively moved toward the fence. \\
2 - Reactive & $\begin{array}{l}\text { The animals showed vigilant behavior: they remained stolid, staring with fixed gaze and } \\
\text { moved the ears toward noises, movement or people; ceased what they were previously } \\
\text { doing and moved away. } \\
\text { The animals walked slowly toward the fence, showed little movement, could be easily } \\
\text { observed and did not interrupt their activities. They stopped without difficulty and } \\
\text { moved in the direction of the observer for curiosity. }\end{array}$ \\
\end{tabular}

Data collection for commercial and pedigree animals during the auction

The amount of time spent on the auction ring, cleanness score and the animals' behavior were analyzed according to the following age ranges: age $1-0$ to 12 months; age $2-13$ to 36 months; age 3 - animals older than 36 months.

The behavior score scale proposed by Piovezan (1998) was adapted to assess the temperament, assigning scores to the animals as they entered and walked around the auction ring, as Table 2 shows. 
Additionally, we observed the number of defecations, urinations and the intensity of vocalizations that took place while the animals were in the auction ring. We also observed eventual falls and injuries and registered the price for each lot.

\section{Statistical Analysis}

The variables we assessed were flight zone, the noise emitted by the lot, number of animals per lot, permanence on the auction ring and lot final price. These variables were submitted to an analysis of variance and we applied the Tukey's test at a significance level of 5\% if F-test was significant. The reactivity scores upon loading and arrival were analyzed individually using electronic Excel $^{\odot}$ spreadsheets and evaluated through the non-parametric Chisquare $\left(\chi^{2}\right)$ test.

Table 2 Behavior scores of the animals entering and walking around the auction ring, and cleanness score.

\begin{tabular}{|c|c|}
\hline Scores & Characterization of the animals' behavior \\
\hline \multirow[t]{3}{*}{ Entrance Score (ES) } & $1-$ no help to enter the auction ring: they enter alone as the gates are open; \\
\hline & $\begin{array}{l}2 \text { - help to enter the auction ring required: once the gates are open, the animals need to } \\
\text { be led to the auction ring with the use of bells or similar tools; }\end{array}$ \\
\hline & $\begin{array}{l}3 \text { - resistance to enter the auction ring: once the gates are open, the animal resists more } \\
\text { than once to enter and is conducted with the help of bells or similar tools. }\end{array}$ \\
\hline \multirow[t]{3}{*}{ Movement Score (MS) } & 1 - animal walks smoothly and calmly; \\
\hline & 2 - animal walks, sometimes trots: runs at times and moves away slightly; \\
\hline & 3 - animal bumps its head, constantly trots: runs and retreats with the other animals. \\
\hline \multirow[t]{2}{*}{ Cleanness Aspect } & $\begin{array}{l}1 \text { - clean lot: animals do not present dirtiness such as mud, feces or dirt below hock } \\
\text { level; }\end{array}$ \\
\hline & $\begin{array}{l}2 \text { - dirty lot: animals with mud, feces or any other kind of dirtiness over the whole body } \\
\text { or most of it. }\end{array}$ \\
\hline
\end{tabular}

\section{Results and Discussion}

\section{Characterization of Loading and Arrival}

As soon as the trucks entered the park, they were led to the arrival ramp to allow the animals to unload. They frequently left the truck with the help of prods or electric shock and were led to the corral to wait. The commercial animals were directly conducted to the corrals, whereas pedigree animals were taken to the showers to be cleaned before heading to the corral.

The number of animals per lot varied according to their origin: lots of pedigree animals were composed of up to four animals, and frequently a lot consisted of one single animal. On the other hand, lots of commercial animals were composed of 25 animals on average. This led to a high number of animals falling and being stomped on during unloading.

The unloading time was highly variable. However, the average unloading time was of 2 minutes for the whole lot to leave the trucks.

Commercial animals only had access to water during their stay in the park. Pedigree cattle, on the other hand, were provided with water, food and showers.

The age affected $(\mathrm{P}<0.05)$ the reactivity scores of commercial animals at arrival (Table 3 ).

The percentage of reactive lots was higher for all ages, which is explained by the number of people present in the corral upon arrival - a cause of stress and agitation to the animals. The most reactive animals were those aged less than a year $(74.7 \%)$ and more than three years $(75 \%)$. The younger animals' reactivity is likely due to fear and also to the fact it was the first time they left their natural habitat. The older animals' higher reactivity was caused by the adoption of a new handling system. As reported by Maffei (2009), the animal's behavioral response depends on the environment and the type of raising and handling; animals become more reactive in the presence of humans. We also assigned scores of 3 - docile animals - among the lots, which reflects their adaptability to intense handling. A lower percentage of lots was classified as very reactive, with agonistic reactions to the new environment, audience and effects of traveling.

There was no difference among commercial categories at loading $(\mathrm{P}>0.05)$. Since they are more accustomed to contact with visitors and handling, they would be more at ease with the condition of being exhibited. Thus, $50 \%$ of the animals of all three age ranges were reactive at loading. Braga et al (2011) associate higher reactivity to Nellore or crossbreed cattle, which run in the stalls and tend to leave the truck simultaneously.

Maffei (2009) stated that the number of reactive lots decreases as age increases. The researcher did not find reactivity differences in groups of Nellore cattle with a maximum age gap of three months. Several studies show that the reactivity of cattle increases with age; others associate improvements to better handling conditions, in which animals 
that do not suffer stress tend to have more docile temperament (Sato 1981; Kabuga and Appiah 1992; Boivin et al 1992; Fordyce and Goddard 1984; Csiro 1988).

Pedigree animals belonging to the three distinct age ranges did not react in a similar fashion upon arrival $(\mathrm{P}<$ 0.05 ), so age was a factor of influence on the results (Table 4).
Since they are breeder animals, they are handled in distinct ways and the animal density in trucks during transportation is lower. The percentage of non-reactive lots was, then, considerable.

Table 3 Number and percentages of lots and animal reactivity scores upon loading and arrival at the exhibition park for commercial beef cattle according to age groups.

\begin{tabular}{lcccc}
\hline Age & Very Reactive & Reactive & Docile Animals & $P$-value \\
\hline$<1$ year & $1(0.8 \%)$ & $86(74.7 \%)$ & Arrival & \\
1 to 3 years & $2(2.2 \%)$ & $50(55.5 \%)$ & $38(42.2 \%)$ & 0.03905 \\
$>3$ year & $1(2.7 \%)$ & $27(75.0 \%)$ & $8(22.2 \%)$ & \\
\hline & & & $52(45.2 \%)$ & \\
\hline$<1$ year & $5(4.3 \%)$ & $58(50.4 \%)$ & $38(42.2 \%)$ & \\
1 to 3 years & $7(7.7 \%)$ & $45(50.0 \%)$ & $18(50.0 \%)$ & \\
$>3$ year & $0(0.0 \%)$ & $18(50.0 \%)$ & & \\
\hline
\end{tabular}

Table 4 Number and percentages of lots and animal reactivity scores upon loading and arrival at the exhibition park for pedigree beef cattle according to age groups.

\begin{tabular}{lcccc}
\hline Age & Very Reactive & Reactive & Docile Animals & $P$-value \\
\hline$<1$ year & $0(0.0 \%)$ & $1(16.6 \%)$ & $5(83.3 \%)$ & \\
1 to 3 years & $0(0.0 \%)$ & $1(33.3 \%)$ & $2(66.6 \%)$ & 0.02329 \\
$>3$ years & $6(17.6 \%)$ & $13(38.2 \%)$ & $15(44.1 \%)$ & \\
\hline & & \multicolumn{2}{c}{ Loading } \\
\hline 1 year & $0(0.0 \%)$ & $2(33.3 \%)$ & $4(66.6 \%)$ & 0.2274 \\
1 to 3 years & $0(0.0 \%)$ & $0(0.0 \%)$ & $3(100.0 \%)$ & \\
$>3$ year & $0(0.0 \%)$ & $18(48.6 \%)$ & $19(51.3 \%)$ & \\
\hline
\end{tabular}

Pedigree animals are usually subject to different loading, transportation and arrival conditions compared with commercial cattle, which usually travel less. The former category had higher percentage of docile animals (Table 4). Pedigree animals possess higher market value and are handled, hence, in distinct ways (bigger corrals containing a smaller number of animals, in addition to water and food supply). Considering that, reactivity is attributed to unpleasant experiences - and they rarely occur with this type of animal, we can explain why they were scored as docile.

Pedigree animals did not present very reactive scores at loading. Apart from that, the percentage of reactive animals was smaller, which also shows that they were adapted to the type of handling adopted during their stay in the park.

Prinzerberg et al (2006) carried out a study in Germany and reported that demand for good-temperament animals impacts on safe and rapid handling. Likewise, nervous or reactive animals are not desired, for they can represent a high risk for the handlers and themselves and even generate additional costs in production (Aguilar et al 2004).

The reactivity scores between male and female cattle were significantly different $(\mathrm{P}<0.05)$, as shown in Table 5 . $78.08 \%$ of females were more reactive than males upon arrival, and there was also a smaller percentage of docile lots among the former. 
Table 5 Number and percentages of lots for each animal reactivity score upon loading and arrival at the exhibition park for commercial beef cattle according to sex.

\begin{tabular}{|c|c|c|c|c|c|}
\hline Sex & Very Reactive & Reactive & Docile Animals & $\chi^{2}$ & $P$-value \\
\hline \multicolumn{6}{|c|}{ Arrival } \\
\hline Female & $2(2.7 \%)$ & $57(78.0 \%)$ & $14(19.1 \%)$ & & \\
\hline Male & $2(1.2 \%)$ & $106(63.1 \%)$ & $60(35.7 \%)$ & 6.9576 & 0.0308 \\
\hline Average (\%) & $1.9 \%$ & $70.5 \%$ & $27.4 \%$ & & \\
\hline \multicolumn{6}{|c|}{ Loading } \\
\hline Female & $6(8.2 \%)$ & $35(47.9 \%)$ & $32(43.8 \%)$ & & \\
\hline Male & $6(3.5 \%)$ & $86(51.2 \%)$ & $76(45.2 \%)$ & 17.6611 & 0.3108 \\
\hline Average (\%) & $5.8 \%$ & $49.5 \%$ & $44.5 \%$ & & \\
\hline
\end{tabular}

There was no difference $(\mathrm{P}>0.05)$ between males and females commercial and pedigree at loading. Maffei (2009) claims that males tend to be less reactive than females. Although the animals' sex is genetically determined, it can influence on the cattle's temperament as a non-genetic factor. Several other studies report females as being more aggressive, rendering handling more difficult (Gauly et al 2002; Maffei et al 2006; Prinzenberg et al 2006).

Hard and Hansen (1985) attributed females' more aggressive behavior to hormonal factors, since hormonal interaction fluctuates more in females than in males. According to Menezes (2014), carcasses of females have more injuries than those of males, which is possibly related to their highest reactivity.
This higher reactivity observed in females could, then, result in more difficult handling due to flight attempts, collision against the boards of the facilities and consequent muscular fatigue, falls in the truck and lower meat quality (Mach et al 2008).

Table 6 presents data referring to the sex of pedigree animals. No significant differences $(\mathrm{P}>0.05)$ were observed between pedigree males and females at arrival. On average, $50.76 \%$ of the animals were docile during unloading.

A significant difference $(\mathrm{P}<0.05)$ was observed between males and females at loading: $70 \%$ of the females were more reactive than males $(26 \%)$, whereas $50.7 \%$ of the lots were classified as docile.

Table 6 Number and percentages of lots for each animal reactivity score upon loading and arrival at the exhibition park, for pedigree beef cattle according to sex.

\begin{tabular}{|c|c|c|c|c|}
\hline Sex & Very Reactive & Reactive & Docile Animals & $\chi^{2}$ \\
\hline & \multicolumn{4}{|c|}{ Arrival } \\
\hline Female & $2(10.0 \%)$ & $9(45.0 \%)$ & $9(45.0 \%)$ & \\
\hline Male & $4(17.4 \%)$ & $6(26.0 \%)$ & $13(56.5 \%)$ & 0.4079 \\
\hline \multirow[t]{2}{*}{ Average } & $13.7 \%$ & $35.5 \%$ & $50.7 \%$ & \\
\hline & \multicolumn{4}{|c|}{ Loading } \\
\hline Female & $0(0.0 \%)$ & $14(70.0 \%)$ & $6(30.0 \%)$ & \\
\hline Male & $1(4.3 \%)$ & $6(26.0 \%)$ & $16(69.5 \%)$ & 0.0137 \\
\hline Average & $2.1 \%$ & $48.0 \%$ & $49.7 \%$ & \\
\hline
\end{tabular}

Such results show the importance of reactivity assessment in pedigree animals, given the fact they are sold for genetic purposes. Fordyce et al (1992) affirm that cows with better temperament had higher conception rates than those with worse temperament scores.

The flight zone varied $(\mathrm{P}<0.05)$ according to the reactivity score, age and traveling time. Lots of animals with aggressive and docile scores had longer flight zones. This result can be explained by the fact that very aggressive animals show the behavior of moving toward the fence when threatened or in the presence of humans, hence the shorter flight zones.

Animals older than a year were more distant from the fence, which may be explained because they might have been experienced similar stressful situations in the past, or had difficulty trying to adapt to new environments or handling types. In relation to traveling time, the longer the trip, the 
shorter the flight zones in the corral, which probably reveals a state of exhaustion.

The drivers' behavior was revealed to have an impact on the results $(\mathrm{P}<0.05)$ and the frequency of the use of electric prods was higher in lots containing fewer animals. The opposite happened with traveling time, in which a greater number of animals were transported on long-distance trips. It is more practical for cattle owners to transport larger quantities of animals on long-distance journeys.

None of the variables studied had any influence $(\mathrm{P}>$ $0.05)$ on the sounds emitted by the animals. The values were under $85 \mathrm{~dB}(\mathrm{~A})$ - the threshold above which both humans and animals can develop hearing impairment, generating stress and irritability.

There was no difference $(\mathrm{P}>0.05)$ on pedigree animals' flight zone and traveling time in relation to aggressiveness score, age and driver's behavior. Such results were expected because the type of handling adopted for these animals in the parks was distinct: pedigree animals are accommodated in larger, lower-density corrals, are showered before heading toward the corral and have access to food and water after unloading. Such conditions, combined with careful handling, have lower stress levels at arrival as an outcome.

Although handling in the corral is aligned with the national system guidelines, electric shock was adopted at arrival to lead the animals to exit the truck. Under these conditions, animals are usually scared, or drivers are hurried.

It became necessary to use electric shock in lots containing larger numbers of animals, most of them being of females.

As Grandin (1997) claims, indicators such as flight zone, vocalization and kicks are behavioral parameters that can be used for stress assessment. Longer flight zones are indicative of more aggressive temperaments (Fordyce et al 1984).

\section{Characterization of the animals during the auction}

Animals belonging to all three age ranges reacted in distinct ways while entering the ring auction $(\mathrm{P}<0.05)$. Around $70 \%$ of lots of younger animals (less than one year old) entered the ring auction without external help. This fact is attributed to anxiety and restlessness, which cause the animals to move more intensely.

The same occurred for animals older than three years $(58.3 \%)$. In this case, however, this is due to more frequent contact with humans. The animals between one to three years old needed help to enter the auction ring due to the sudden change of environment: they moved from the corral (usually dimly lit) to enter the auction ring with stronger lights and higher noise levels. It can, therefore, lead to reluctance.

The data shown in Table 7 show that there was no difference $(P>0.05)$ in the pedigree animals' entrance, according to the age range. This is attributed to three factors: they are adapted to the type of handling; they are accustomed to being part of events outside the farms and the number of animals per lot was smaller.

Silveira et al (2010) did not find the same results. They assessed the behavior of the animals on the auction ring, attributing the same scores used in the present study, and concluded that younger animals show more resistance when entering the auction ring. As age increases, animal-human contact becomes more frequent. They claim, additionally, that younger animals tend to be more reactive because they had less contact with auctions and fear the situation.

Table 8 shows that animals belonging to the distinct age ranges did not react in the same way $(\mathrm{P}<0.05)$, and therefore differences in movement in the auction ring could be observed.

The highest percentage of lots had animals with the habit of walking calmly, regardless of age $(77.4 \% ; 45.5 \%$ and $63.8 \%$ ). This shows that the animals remained calm when the auctions took place.

The association of data from Tables 8 and 9 reveals that the number of defecations and urinations, as well as the intensity of vocalizations, were low. Furthermore, there were no significant differences due to age, which justified the movement of the animals in the auction ring.

There was no difference $(\mathrm{P}>0.05)$ in the movement ccore for pedigree cattle, and $100 \%$ of the animals aged between 1 to 3 years trotted intensely. This can be explained by the low number of animals per lot.

Grandin (2000) and Lanier (2000) associate the increased movement of the animals to the aversive stimuli they were subject to. Silveira et al (2006) showed that zebu cattle moved more intensely in the auction ring than cattle of European origin.

Table 10 presents the data on the entrance in the auction ring according to sex. There was no difference $(\mathrm{P}>$ $0.05)$ between males and females. However, most animals entered the auction ring with no need for help $(56.1 \%$ and $56.5 \%$, respectively). Pedigree animals showed a difference between the sex category, in which females (75\%) needed more help to enter the auction ring. 
Table 7 Number and percentages of lots for each animal reactivity score at the entrance in the ring auction in agricultural shows in Northern Minas Gerais according to the commercial and pedigree cattle's age ranges.

\begin{tabular}{lccccc}
\hline Age & With help & Without help & Resistance to enter & $\chi^{2}$ & $P$-value \\
\hline & & \multicolumn{2}{c}{ Commercial } & \\
\hline < year & $81(70.4 \%)$ & $31(26.9 \%)$ & $3(2.6 \%)$ & & \\
1 to 3 years & $34(37.7 \%)$ & $49(54.4 \%)$ & $7(7.7 \%)$ & 22.2591 & 0.00017 \\
$>3$ years & $21(58.3 \%)$ & $13(36.1 \%)$ & $2(5.5 \%)$ & & \\
\hline & & & & \\
\hline 1 year & $4(66.6 \%)$ & $2(33.3 \%)$ & $0(0.0 \%)$ & & \\
1 to 3 years & $0(0.0 \%)$ & $3(100.0 \%)$ & $0(0.0 \%)$ & 7.4499 & 0.1158 \\
$>3$ years & $7(20.6 \%)$ & $24(70.6 \%)$ & $3(8.8 \%)$ & & \\
\hline
\end{tabular}

Table 8 Number and percentage of lots for each Movement Score (MS) in the auction ring in agricultural shows in northern Minas Gerais according to commercial and pedigree cattle's age.

\begin{tabular}{lcccc}
\hline Age & Walks calmly & Sometimes trots & Trots constantly & $P$-value \\
\hline$<1$ year & $89(77.4 \%)$ & $24(20.87)$ & $2(1.73)$ & \\
1 to 3 years & $41(45.5 \%)$ & $37(41.11)$ & $12(13.33)$ & 0.00002 \\
$>3$ year & $23(63.8 \%)$ & $8(22.22)$ & $5(13.89)$ & \\
\hline & & Pedigree & \\
\hline$<1$ year & $3(50.0 \%)$ & $3(50.0 \%)$ & $3(0.0 \%)$ & 0.1158 \\
1 to 3 years & $0(0.0 \%)$ & $0(0.0 \%)$ & $9(26.4 \%)$ & \\
$>3$ year & $5(14.7 \%)$ & $20(58.8 \%)$ & & \\
\hline
\end{tabular}

Table 9 Average values and percentage of animals as a function of behavior shown in the auction ring.

\begin{tabular}{lccc}
\hline Age & Vocalization intensity $(\mathrm{dB})$ & Number of defecations & Number of urinations \\
\hline$<1$ year & $0.08(0.0 \%)$ & $0.48(0.2 \%)$ & $0.79(0.2 \%)$ \\
1 to 3 years & $0.09(0.0 \%)$ & $0.58(0.2 \%)$ & $0.67(0.2 \%)$ \\
$>3$ years & $0.14(0.0 \%)$ & $0.41(0.1 \%)$ & $0.61(0.2 \%)$ \\
\hline
\end{tabular}


Table 10 Number and percentages of lots of commercial and pedigree animals for each Entrance Score (ES) in auction rings in northern Minas Gerais according to sex.

\begin{tabular}{lccccc}
\hline Age & No help needed & Help needed & Resistance to enter & $\chi^{2}$ & $P$-value \\
\hline Females & $41(56.1 \%)$ & $25(34.2 \%)$ & $7(9.6 \%)$ & \\
Males & $95(56.5 \%)$ & $68(40.4 \%)$ & $5(3.0 \%)$ & 4.9822 & 0.08281 \\
\hline \multicolumn{5}{c}{ Pedigree } \\
Females & $2(10.0 \%)$ & $15(75.0 \%)$ & $3(15.0 \%)$ & & \\
Males & $6(26.0 \%)$ & $8(34.7 \%)$ & $9(39.1 \%)$ & 6.9549 & 0.03088 \\
\hline
\end{tabular}

Table 11 shows no difference $(\mathrm{P}>0.05)$ in the MS score for either commercial or pedigree animals, taking sex into account. Thus, the walking calmly score was assigned to $63.7 \%$ of the commercial animals, whereas the commercial animals received the sometimes trots score (67\%) more frequently. It shows that sex did not influence the movement of the animals.

Silveira et al (2006) found different results when assessing cattle's behavior on auction tracks. Females had higher Entrance and Movement scores. Lanier et al (2000) studied 1,636 animals on auction rings and found cows to be more reactive than bulls.

Table 12 shows the relationship between the cleanness score and price. There was no difference $(\mathrm{P}<0.05)$ on the visual aspect of males aged between 1 and 3 years. It suggests that, for this category, appearance and behavior-related issues do not have a significant impact on commercial transactions. The main concern is to acquire animals for breeding and weight gain purposes.

Table 11 Number and percentages of lots of commercial and pedigree animals for each Movement Score (MS) in auction rings in northern Minas Gerais according to sex.

\begin{tabular}{lcccc}
\hline Age & Walks calmly & Sometimes trots & Trots constantly & $P$-value \\
\hline \multicolumn{5}{c}{ Commercial } \\
\hline Females & $47(64.3 \%)$ & $19(26.0 \%)$ & $7(9.5 \%)$ & \\
Males & $106(63.0 \%)$ & $50(29.7 \%)$ & $12(7.1 \%)$ & 0.7234 \\
\hline Average & $63.73 \%$ & $27.28 \%$ & $8.36 \%$ & \\
\hline \multicolumn{5}{c}{} \\
Females & $5(25.0 \%)$ & $12(60.0 \%)$ & $3(15.0 \%)$ & 0.1524 \\
Males & $6(26.0 \%)$ & $17(73.9 \%)$ & $0(0.0 \%)$ & \\
\hline Average & $25.5 \%$ & $67.0 \%$ & $7.5 \%$ & \\
\hline
\end{tabular}

Table 12 Average price $(\mathrm{R} \$)$ per animal according to the cleanness score at auction.

\begin{tabular}{|c|c|c|c|c|}
\hline Sex & Clean lot & Dirty lot & CV (\%) & $\operatorname{Pr}>\mathrm{Fc}$ \\
\hline \multicolumn{5}{|c|}{ Commercial } \\
\hline Females $<1$ year & $799.52^{\mathrm{a}}$ & $676.36^{\mathrm{a}}$ & 26.24 & 0.1183 \\
\hline Males $<1$ year & $889.20^{\mathrm{a}}$ & $893.39^{\mathrm{a}}$ & 23.28 & 0.9341 \\
\hline Females 1 to 3 years & $736.00^{\mathrm{a}}$ & $852.63^{\mathrm{a}}$ & 26.92 & 0.2444 \\
\hline Males de 1 to 3 years & $908.60^{\mathrm{b}}$ & $1096.66^{\mathrm{a}}$ & 22.86 & 0.0018 \\
\hline Females $>3$ years & $846.00^{\mathrm{a}}$ & $1072.00^{\mathrm{a}}$ & 35.01 & 0.1804 \\
\hline Males $>3$ years & $1154.00^{\mathrm{a}}$ & $1257.50^{\mathrm{a}}$ & 24.87 & 0.4753 \\
\hline \multicolumn{5}{|c|}{ Pedigree } \\
\hline Females $>3$ years & $4580.00^{\mathrm{a}}$ & $4960.00^{\mathrm{a}}$ & 13.86 & 0.2612 \\
\hline Males $>3$ years & $5367.27^{\mathrm{a}}$ & $5616.00^{\mathrm{a}}$ & 12.56 & 0.5112 \\
\hline
\end{tabular}


For the remaining categories, there was no difference ( $\mathrm{P}>0.05)$ regarding the animals' dirtiness. The results for pedigree animals were not significantly different because such animals were showered immediately after their arrival at the park and, consequently, the visual scores were similar. The hypothesis that clean and calm animals have higher prices is a tendency shown by the audience of virtual auctions.

The public attending auctions in northern Minas Gerais worry about the demands of the commercial market (Carvalho et al 2019), including animal welfare issues. They choose, however, on the basis of genetic and bodily-score related factors.

\section{Conclusions}

Sex and age influence animals' reactivity upon arrival. Flight zones are influenced by the type of handling received and the reactivity of the animals. Factors such as noise, number of animals per lot and traveling time also had an impact on the reactivity of the lots.

The distinct ages and sex of the animals influenced on the temperament, both on the entrance and while moving on the auction ring. The visual aspect affects the price of male animals aged between 1 and 3 years. Nonetheless, it is not the most frequent parameter used by cattle buyers.

\section{Conflict of Interest}

The authors declare no conflict of interest.

\section{References}

ABIEC - Associação brasileira das indústrias exportadoras de carnes bovinas (2019) Perfil da pecuária no Brasil. Disponível em: http://www.abiec.com.br/controle/uploads/arquivos/s umario2019portugues.pdf. Acesso em: 17 setembro de 2019.

Barbosa SID, Fischer V, Mendonça G (2006) Comportamento de bovinos de corte em pista de remate. Ciência Rural 36:1529-1533.

Boivin X, Le Neindre P, Chupin JM (1992) Influence of early management on ease of handling and open-field behavior of cattle. Applied Animal Behaviour Science 32:313- 323.

Braga JS, Paranhos CMJR, Páscoa AG, Borges TD, Franco MR, Pellecchia AJR, Soares DR (2011). Avaliação de efeito de dois grupos raciais no manejo de bovinos em frigorífico. In: Alpa - XXII Reunión de La Asociación Latinoamericana de Producción Animal. Montevideo, Uruguay. Anais... Alpa.

Carvalho CCS, Costa MD, Goncalves MCM, Diniz TA, Silva GC, Ferreira HC, Pereira KCB, Castro ALO, Santos LV (2019) Animal and workers' welfare during agricultural fair. Journal of Animal Behaviour and Biometeorology 7:78-85.

Csiro (1998) Genetic and environment methods of improving the temperament of Bosindicus and crossbred cattle. Queenland: Australian Meat Research Comittee (Final Report).

Figueiredo LG, Pereira EJ, Barreto MG, Sterman FJB, Carvalho BJC, Chicaroni M (2005) Análise genética do temperamento em uma população da raça Nelore. Livestock Research for Rural Development 17:1-7.

Fordyce G, Goddard ME (1984) Maternal influence on temperament of Bosindicus cross cows. Proceeding of the Australian Society of Animal Producion 15:345-438.

Fordyce G, Burrow HM (1992) Temperament of Bosindicus bulls and its influence on reprodutive efficiency in the tropics. In: Workshop bull fertility Proceedings... Rockhampton 1:35-37.

Gauly M, Mathiak H, Erhardt G (2002) Genetic background of behavioural and plasma cortisol response to repeated shortterm separation and tethering of beef calves Journal of Animal Breeding and Genetics 119:379-384.

Grandin T (1997) Assessment of stress during handling and transport. Journal of Animal Science 75:249-257.

Grandin T (2000) Introduction management and economic factors of handling and transport. In: T. Grandin. (ed) Livestock Handling and Transport 2ed. CABI, Wallingford, pp 1-14.

Hard E, Hansen S (1985) Reduced fearfulness in the lactating rat. Physiology and Behavior 35: 641-643.

Hoffmann A, Moraes EHBK, Mousquer CJ, Simioni TA, Gomes JF, Ferreira BD, Silva HM (2014) Produção de bovinos de corte no sistema de pasto-suplemento no período da seca. Nativa 2:119-130.

Kabuga JD, Appiah P (1992) A note on the ease of handling and flight distance of Bosindicus, Bos Taurus and its crosses. Animal Production 54:309-311.

Lanier JL, Grandin TR, Green D, Avery D, McGee EK (2000) The relationship between reaction to sudden, intermittent movements and sounds and temperament. Journal of Animal Science 78:1467-1474.

Mach N, Bach A, Velarde A, Devant M (2008) Association between animal, transportation, slaughterhouse practices, and meat $\mathrm{pH}$ in beef. Meat Science 78:232-238.

Maffei WE (2009) Reatividade animal. Revista Brasileira de Zootecnia 38:81-92.

Maffei WE, Bergmann JAG, Pinotti M (2006) Reatividade em ambiente de contenção móvel: uma nova metodologia para avaliar o temperamento bovino. Arquivo Brasileiro de Medicina Veterinária e Zootecnia 58:1123-1131.

Menezes LM (2014) Temperamento, comportamento ao parto e desempenho de bovinos de corte de diferentes genótipos. Tese, Faculdade de Agronomia Eliseu Maciel.

Piovesan U (1998) Análise de Fatores Genético e Ambientais na Reatividade de quatro raças de Bovinos de corte ao manejo, Dissertação, Universidade Estadual Paulista.

Prinzenberg EM, Brandt H, Müllenhoff A, Gauly M, Erhardt G (2006) A phenotypic and genetic approach to temperament in German beef cattle. In: $8^{\circ}$ World congress on genetics applied to livestock production, Belo Horizonte. Proceedings... Belo Horizonte: Instituto Prociência 17-28.

Sato S (1981) factors associated with temperament of beef cattle. Japanese Journal of Zootech Science 52:595-605

Silveira IDB, Fischer V, Mendonça G (2010) Efeito do genótipo e da idade de ovinos na reatividade medida em pista de venda. Revista Brasileira de Zootecnia 39:2304-2309.

Silveira IDB, Fischer V, Mendonça G (2006) Comportamento de bovinos de corte em pista de remate. Ciência Rural 36:1529-1533. 